\title{
Properties of ZnO Nanopowders Synthesized by Glycine-Nitrate Gel Combustion
}

\author{
Ö. Yildiz ${ }^{a, *}$, A.M. SOYdAN ${ }^{b}$, E.F. $\operatorname{IPÇIZADE}^{b}$, D. AKIn ${ }^{b}$ AND Ö. UÇAK \\ ${ }^{a}$ Kocaeli University, Faculty of Engineering, Department of Metallurgical and Materials Engineering \\ TR-41380 Kocaeli, Turkey \\ ${ }^{b}$ Gebze Institute of Technology, Faculty of Engineering, Department of Materials Science and Engineering \\ TR-41400 Gebze/Kocaeli, Turkey
}

\begin{abstract}
The morphology and other physical properties of $\mathrm{ZnO}$ nanopowders synthesized by glycine-nitrate gel combustion process were investigated and characterized by scanning electron microscopy, transmission electron microscopy, nanosizer and X-ray diffraction. Glycine, $\mathrm{NH}_{2} \mathrm{CH}_{2} \mathrm{COOH}$, and zinc nitrate $\mathrm{Zn}\left(\mathrm{NO}_{3}\right)_{2} \cdot 6 \mathrm{H}_{2} \mathrm{O}$ were dissolved in distilled water and the solution was coagulated by mixing at $90^{\circ} \mathrm{C}$. The viscous gel prepared during glycine-nitrate mixing was heated at $\approx 220^{\circ} \mathrm{C}$ to initiate the exothermic reactions by self-combustion where the temperature reached up to $1200{ }^{\circ} \mathrm{C}$. The glycine-nitrate ratio had a significant effect on the reaction temperature and final particle morphology. Therefore the synthesized powders have a different morphology like formless and spherical tufa ash. The particle size distribution was 50-1200 $\mathrm{nm}$ as measured using a nanosizer.
\end{abstract}

DOI: 10.12693/APhysPolA.125.664

PACS: 81.20.Ka, 81.07.Wx, 61.46.Df, 81.07.-b

\section{Introduction}

$\mathrm{ZnO}$ has a wide range of uses in high technology applications such as gas, chemical and biological sensors, flat screen displays, UV light emitters and switches, catalysts and pigments [1-4]. $\mathrm{ZnO}$ nanopowders with different physical properties can be synthesized by various chemical techniques like precipitation, sol-gel, micro emulsion, thermal decomposition, spray pyrolysis, electro deposition, microwave-assisted techniques, chemical vapor deposition, and hydrothermal methods. The glycinenitrate process (GNP) or glycine-nitrate gel combustion (GNGC) is a very simple, fast and low cost process for synthesis of oxide nanopowders [5-8].

In this study, the morphology and other physical properties of $\mathrm{ZnO}$ nanopowders synthesized by GNGC were characterized by different methods. The final powder properties were controlled by process parameters like the molar ratio of glycine to nitrate $(\psi)$ and the condition in the process reactor.

\section{Experimental}

Glycine $\mathrm{NH}_{2} \mathrm{CH}_{2} \mathrm{COOH}$ and zinc nitrate $\mathrm{Zn}\left(\mathrm{NO}_{3}\right)_{2} \cdot 6 \mathrm{H}_{2} \mathrm{O}$ were used as starting raw materials with a purity of $\approx 99.5 \mathrm{wt} \%$ from Alfa Aesar.

\subsection{Synthesis of $Z n O$ nanopowders}

$\mathrm{NH}_{2} \mathrm{CH}_{2} \mathrm{COOH}$ and $\mathrm{Zn}\left(\mathrm{NO}_{3}\right)_{2} \cdot 6 \mathrm{H}_{2} \mathrm{O}$ were dissolved in distilled water with different molar ratios (Table). The solution was coagulated by mixing during heating at $90^{\circ} \mathrm{C}$ to evaporate water and obtain the viscose gel. The prepared viscous gel was perfectly dried and then heated at $\approx 220^{\circ} \mathrm{C}$ to initiate exothermic reactions by

\footnotetext{
*corresponding author; e-mail: oyildiz@kocaeli.edu.tr
}

self-combustion. This occurred suddenly in a single step and when temperatures of up to $1200^{\circ} \mathrm{C}$ were reached [8]. After gel combustion, $\mathrm{ZnO}$ nanopowder was formed as a product by decomposition of the precursor. This appeared in soft agglomerate and crystalline structures, in a volcano ash like tufa form.

Molar ratio of glycine to zinc nitrate

TABLE

for synthesis of $\mathrm{ZnO}$ nanopowders.

\begin{tabular}{c|c|c|c}
\hline \hline \multirow{2}{*}{ No. } & $\mathrm{NH}_{2} \mathrm{CH}_{2} \mathrm{COOH}$ & $\mathrm{Zn}\left(\mathrm{NO}_{3}\right)_{2} \cdot 6 \mathrm{H}_{2} \mathrm{O}$ & \multirow{2}{*}{$\begin{array}{c}\text { Molar ratio } \\
\text { glycine/nitrate }\end{array}$} \\
\cline { 2 - 3 } & \multicolumn{2}{|c}{$[\mathrm{g}]$} & 0.60 \\
1 & 4.50 & 29.75 & 0.80 \\
2 & 6.01 & 29.75 & 1.00 \\
3 & 7.51 & 29.75 & 1.20 \\
4 & 9.01 & 29.75 & 1.30 \\
5 & 9.76 & 29.75 & 1.40 \\
6 & 10.51 & 29.75 & 1.50 \\
7 & 11.26 & 29.75 & 1.60 \\
8 & 12.01 & 29.75 &
\end{tabular}

2.2. Characterization of $\mathrm{ZnO}$ nanopowders

The synthesized $\mathrm{ZnO}$ powders were characterized by scanning and transmission electron microscopy (SEM and TEM), nanosizer, and X-ray diffraction (XRD). Microstructural characterization (morphology, particle shape, and size) of the powder materials were done by SEM and TEM using Philips XL30 SFEG Type and a Philips Tecnai, respectively. The particle size and distribution of the powders were measured using Nanosizer 2000 from Malvern Instruments. The crystallinity and crystal structure were observed using XRD (Rigaku Dmax 2200 Diffractometer; $\mathrm{Cu} K_{\alpha}$ radiation and wavelength of $\lambda=1.54060 \AA$ ).

\section{Results and discussion}

The molar ratio of glycine to nitrate $(\psi)$ directly affected the reaction temperature of the system [8], and the combustion conditions had an important influence 

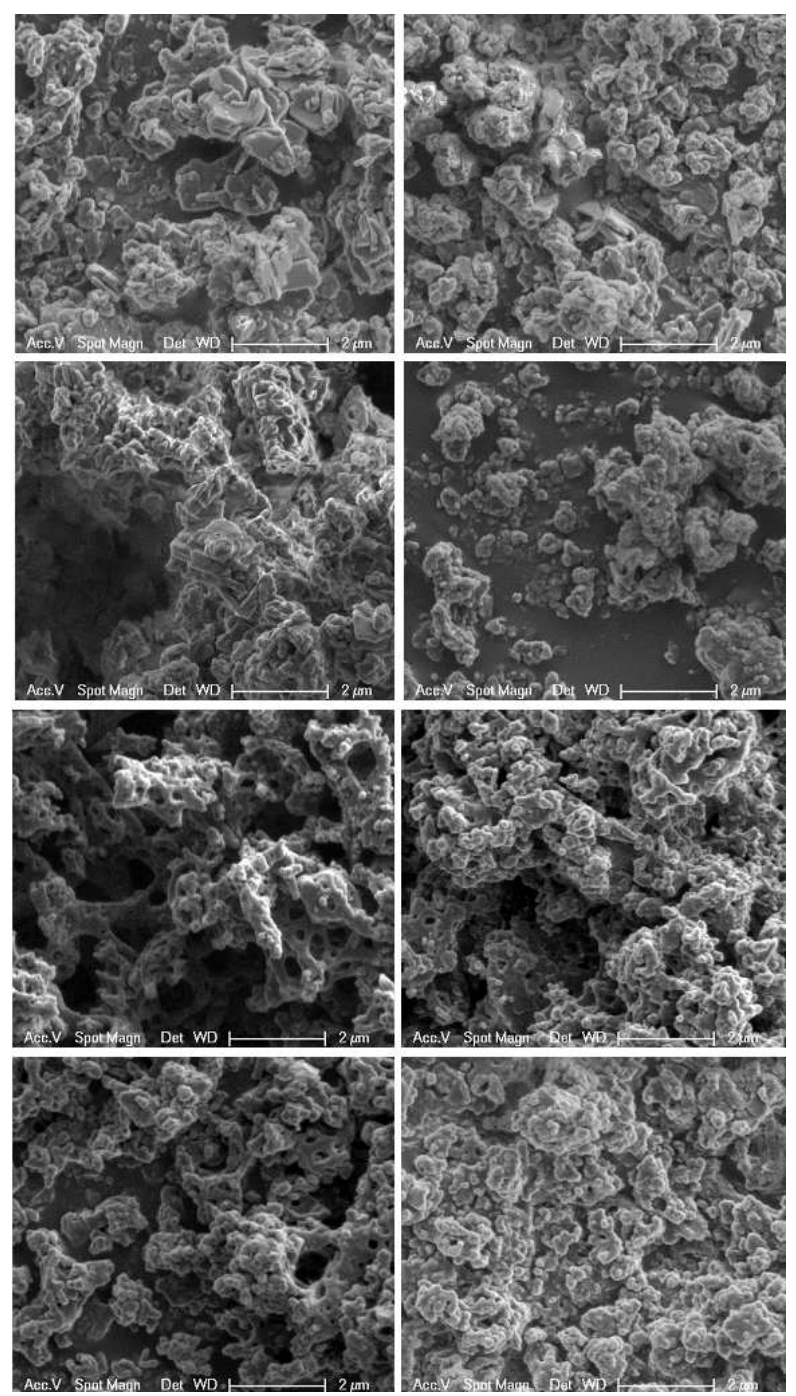

Fig. 1. Morphology of $\mathrm{ZnO}$ nanopowders synthesized by GNGC (samples: $1,2 / / 3,4 / / 5,6 / / 7,8$ ).

on the morphology and other physical properties of $\mathrm{ZnO}$ nanopowders synthesized by GNGC. Hwang and Wu [8] classified the reaction conditions and temperature depending on the glycine-nitrate molar ratio $(\psi)$ : smoldering combustion synthesis (SCS), where $\psi<1.05$, results in a relatively slow and essentially flameless reaction and combustion temperature $\left(T_{\mathrm{c}}\right)<650^{\circ} \mathrm{C}$; volume combustion synthesis (VCS), where $1.05<\psi<1.90,1000^{\circ} \mathrm{C}<$ $T_{\mathrm{c}}<1250^{\circ} \mathrm{C}$ results in a simultaneous and extremely fast reaction; and self-propagating high-temperature synthesis (SHS), $1.90<\psi<3.00,850^{\circ} \mathrm{C}<T_{\mathrm{c}}<1000{ }^{\circ} \mathrm{C}$ where there is a local and slow propagated combustion wave. But, in our studies, we observed that the gel combustion reactions for samples with $1.20 \leq \psi$ given in Table (each sample is $3 \mathrm{~g}$ ) occurred spontaneously, extremely fast, with low flame and an explosive loud noise. Therefore, the experimental studies for all samples given in Table were conducted in a glass beaker within a stainless steel reactor vessel at atmospheric pressure to produce $\mathrm{ZnO}$ nanopowder with adequate amount given in Table (powder product: $\approx 8 \mathrm{~g} \mathrm{ZnO}$ ).

The $\mathrm{ZnO}$ nanopowder synthesized with a $\psi$ between $0.6 \leq \psi \leq 1$ had a massive and large particle size $\leq 1.5 \mu \mathrm{m}$ without porosity in hard agglomerate structure (Fig. 1 (s. 1-3)). Namely, when $\psi$ was under stoichiometric ratio $(\psi \leq 1)$, the combustion occurred explosively and particles grew to large size. If $\psi$ was increased at stoichiometric ratios between $1.2 \leq \psi \leq 1.6$, the combustion occurred at a slow rate and the powders had a soft agglomerate structure and tuff-ash like morphology with microporosity and smaller particle size less than $1 \mu \mathrm{m}$ (Fig. 1 (s. 4-8)). When SEM images of all samples were studied, it was observed that the powder had a smaller particle size and soft agglomerate structure by increase of glycine $(1.2 \leq \psi)$. This effect can also be observed using other particle size analysis techniques (Figs. 2 and 3 ).

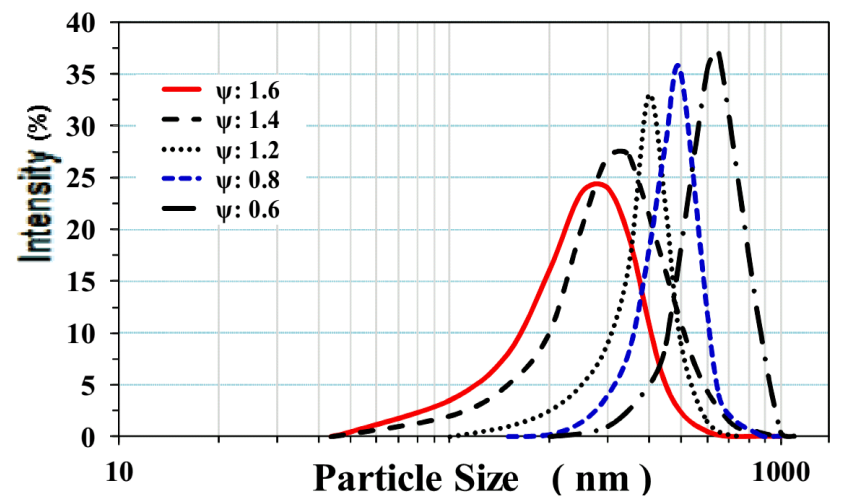

Fig. 2. Particle size analysis of $\mathrm{ZnO}$ nanopowders (samples: 1, 2, 4, 6 and 8).

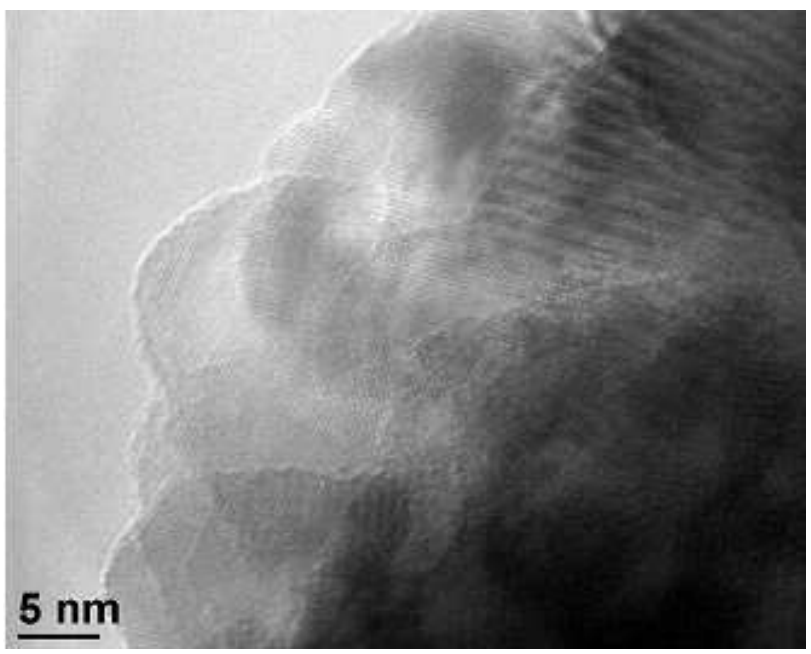

Fig. 3. TEM image of $\mathrm{ZnO}$ nanopowders (sample 4).

Figure 2 showed the particle size analyses performed by nanosizer for samples 1, 2, 4, 6 and 8 . Although the particle size of the synthesized powder (sample 4) was determined as being in the nanoscale between 50 and 


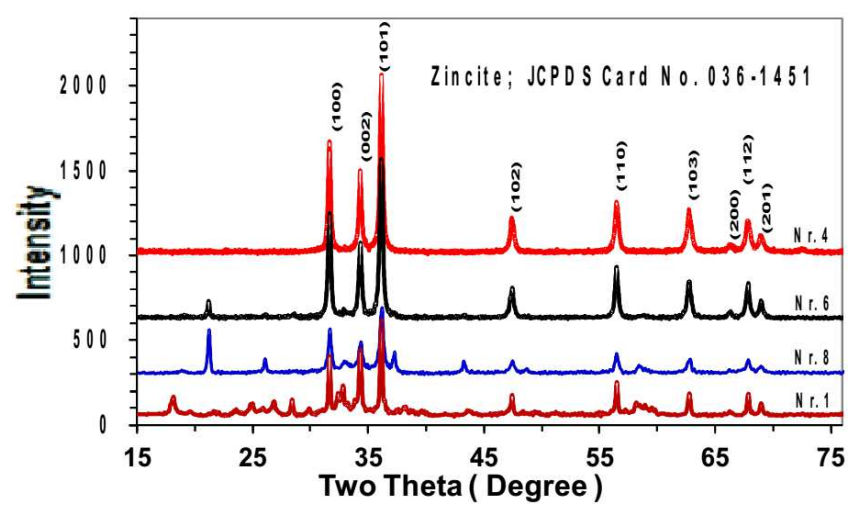

Fig. 4. XRD analysis of $\mathrm{ZnO}$ nanopowders (samples: 1, 4, 6 and 8).

$300 \mathrm{~nm}$ by TEM image analysis (Fig. 3), the nanosizer analysis exhibited that this powder had a large particle size distribution between 100 and $1000 \mathrm{~nm}$ (Fig. 2) because agglomeration of the nanopowders occurred during the particle size measurement.

XRD analysis indicated that the synthesized $\mathrm{ZnO}$ nanopowders (samples 4, 5, and 6) had a crystalline structure of zincite with a JCPDS card No: 00-036-1451 (Fig. 4), although the combustion reaction occurred in $1-5 \mathrm{~s}$. In addition, other diffraction peaks from other phases or trace impurities were not detected in sample 4. The XRD peak intensity of $\mathrm{ZnO}$ powders decreased for the values of $\psi>1.4$ and $\psi \leq 1.0$ (Fig. 4 ). XRD analyses of the powders with a $\psi \leq 0.8$ and $\psi \geq 1.2$ showed impurities from zinc cyanide (JCPDS card No: 00-006-0175) in sample 8 and from zinc nitrate hydrate (JCPDS card No: 00-019-1467) in sample 1. Therefore, these ash powders had a yellowish or light brown color. But, the powders gained a white color after heat treatment at $300{ }^{\circ} \mathrm{C}$ without waiting.

\section{Conclusions}

The synthesis of $\mathrm{ZnO}$ nanopowders by GNGC in an open environment is very dangerous especially for the samples with a glycine: zinc nitrate ratio $\psi \leq 1.0$. The combustion reactions were sudden and extremely fast like an explosion. Moreover, after combustion there was no powder in the reaction vessel. Therefore, the synthesis of $\mathrm{ZnO}$ nanopowders by GNGC should be conducted in a closed reactor vessel under atmospheric pressure.

The molar ratio of glycine to nitrate $(\psi)$ also has an important influence on the morphology and crystallinity of the $\mathrm{ZnO}$ nanopowders. The dissolution of glycine and nitrate in distilled water, the gelation and homogenization process of the prepared solution, and the slow drying of gel at $90^{\circ} \mathrm{C}$ to remove water, influenced the particle characteristics. Samples with a $\psi \leq 1.0$ (samples 1, 2, and 3) exhibited a powder with large particle size and hard agglomerated structure; samples with a high $\psi$ $(\psi \geq 1.4 ; 6,7$, and 8$)$ had a very small particle size and soft agglomerated structure.

\section{Acknowledgments}

The authors thank Ömer Faruk Deniz, Ahmet Nazım, and Adem Şen at Gebze Institute of Technology (GYTE) for friendly help to analyze the powder materials.

\section{References}

[1] O.W. Perez-Lopez, A.C. Farias, N.R. Marcilio, J.M.C. Bueno, Mater. Res. Bull. 40, 2089 (2005).

[2] L. Liao, H.B. Lu, M. Shuai, J.C. Li, Y.L. Liu, C. Liu, Z.X. Shen, T. Yu, Nanotechnology 19, 175501 (2008).

[3] J. Xu, Q. Pan, Y. Shun, Z. Tian, Sensors Actuat. B 66, 277 (2000).

[4] K. Keis, C. Bauer, G. Boschloo, A. Hagfeldt, K. Westermark, H. Rensmo, H. Siegbahn, J. Photochem. Photobiol. A: Chem. 148, 57 (2002).

[5] S.R. Nair, R.D. Purohit, A.K. Tyagi, P.K. Sinha, B.P. Sharma, Mater. Res. Bull. 43, 1573 (2008).

[6] R.K. Lenka, T. Mahata, P.K. Sinha, A.K. Tyagi, J. Alloys Comp. 466, 326 (2008).

[7] N. Riahi-Noori, R. Sarraf-Mamoory, P. Alizadeh, A. Mehdikhani, J. Ceram. Proc. Res. 9, 246 (2008).

[8] C.-C. Hwang, T.-Y. Wu, J. Mater. Sci. 39, 6111 (2004). 